\title{
Green Tea Polyphenols Reduced Fat Deposits in High Fat-Fed Rats via erk1/2-PPAR $\gamma$-Adiponectin Pathway
}

\author{
Chong Tian ${ }^{1,2}$, Xiaolei Ye ${ }^{3}$, Rui Zhang ${ }^{1,2}$, Jia Long ${ }^{1,2}$, Weiye Ren ${ }^{1,2}$, Shibin Ding ${ }^{1,2}$, Dan Liao ${ }^{1,2}$, Xin Jin ${ }^{1,2}$, \\ Hongmei $\mathrm{Wu}^{3}$, Shunqin $\mathrm{Xu}^{2}$, Chenjiang Ying ${ }^{1,2 * a}$
}

1 Department of Nutrition and Food Hygiene, School of Public Health, Tongji Medical College, Huazhong University of Science and Technology, Wuhan, People's Republic of China, 2 Ministry of Education Key Lab of Environment and Health, School of Public Health, Tongji Medical College, Huazhong University of Science and Technology, Wuhan, People's Republic of China, 3 Department of Public Health, WenZhou Medical College, WenZhou, People's Republic of China

\begin{abstract}
Objective: Hypoadiponectinemia contributes to the development of obesity and related disorders such as diabetes, hyperlipidemia, and cardiovascular diseases. In this study we investigated the effects of green tea polyphenols (GTPs) on adiponectin levels and fat deposits in high fat (HF) fed rats, the mechanism of signaling pathway was explored as well.

Methods and Results: Male Wistar rats were fed with high-fat diet. GTPs (0.8, 1.6, $3.2 \mathrm{~g} / \mathrm{L})$ were administered via drinking water. Serum adiponectin and insulin were measured by ELISA, mRNA levels of adiponectin and PPAR $\gamma$ in visceral adipose tissue (VAT) were determined by Real-time PCR, protein levels of PPAR $\gamma$, phospho (p) - PPAR $\gamma$, extracellular signal regulated kinase (erk) $1 / 2$ and p-erk1/2 in VAT were determined by western blot. GTPs treatment attenuated the VAT accumulation, hypoadiponectinemia and the decreased mRNA level of adiponectin in VAT induced by HF. Decreased expression and increased phosphorylation of PPAR $\gamma$ (the master regulator of adiponectin), and increased activation of erk $1 / 2$ were observed in HF group, and these effects could be alleviated by GTPs treatment. To explore the underlying mechanism, VAT was cultured in DMEM with high glucose to mimic the hyperglycemia condition in vitro. Similar to the results of in vivo study, decreased adiponectin levels, decreased expression and increased phosphorylation of PPAR $\gamma$, and elevated erk1/2 phosphorylation in cultured VAT were observed. These effects could be ameliorated by co-treatment with GTPs or PD98059 (a selective inhibitor of erk1/2).
\end{abstract}

Conclusion: GTPs reduced fat deposit, ameliorated hypoadiponectinemia in HF-fed rats, and relieved high glucose-induced adiponectin decrease in VAT in vitro. The signaling pathway analysis indicated that PPAR $\gamma$ regulation mediated via erk $1 / 2$ pathway was involved.

Citation: Tian C, Ye X, Zhang R, Long J, Ren W, et al. (2013) Green Tea Polyphenols Reduced Fat Deposits in High Fat-Fed Rats via erk1/2-PPAR $\gamma$-Adiponectin Pathway. PLoS ONE 8(1): e53796. doi:10.1371/journal.pone.0053796

Editor: Angel Nadal, Universidad Miguel Hernández de Elche, Spain

Received October 5, 2012; Accepted December 3, 2012; Published January 15, 2013

Copyright: ( $) 2013$ Tian et al. This is an open-access article distributed under the terms of the Creative Commons Attribution License, which permits unrestricted use, distribution, and reproduction in any medium, provided the original author and source are credited.

Funding: This work was supported by National Basic Research Program of China (973 Program)(Project No.2012CB722401; http://www.973.gov.cn/Default 3. aspx), National Natural Science Foundation of China (Grant No. 30972473, 81030051,81172674, 81273060; http://www.nsfc.gov.cn/Portal0/default152.htm). The funders had no role in study design, data collection and analysis, decision to publish, or preparation of the manuscript.

Competing Interests: The authors have declared that no competing interests exist.

*E-mail: yingchenjiang@yahoo.com

a Current address: Department of Nutrition and Food Hygiene, School of Public Health, Huazhong University of Science and Technology, Wuhan, People's Republic of China

\section{Introduction}

With a tremendous increase in China, the prevalence of obesity has been rising all over the world in the last few decades [1]. Obesity is a vital risk factor for a number of chronic diseases, such as diabetes, vascular diseases, and cancers. Therefore, prevention of obesity becomes crucial in public health. The medical and surgical methods have been used to treat obesity, however, the adverse effects of these treatments are obvious [2,3]. Usage of dietary agents to prevent or treat obesity could be a safer solution to the problem. Epidemiological and laboratory studies showed that green tea possesses significant anti-obesity, anti-diabetes, and cardio-protective properties $[4,5,6]$. Epigallocatechin 3-gallate (EGCG), the major component of catechines in green tea, was demonstrated to reduce body weight gain in animal models of obesity $[7,8]$. Human intervention studies showed that catechins, the bioactive ingredients of green tea polyphenols (GTPs), decreased body weight and affected markers of obesity in healthy, obese and diabetic conditions [9-11]. These data indicated that tea polyphenols are potentially powerful agents in the prevention of obesity. It was suggested that tea decreases body weight gain by reducing lipid and carbohydrate absorption, increasing lipid and carbohydrate utilization, and lessening the lipogenesis, but the mechanism of tea's anti-obesity effects is still inconclusive.

Adiponectin (also referred to as GBP-28, apM1, AdipoQ and Acrp30) is an adipocytokine exclusively secreted by adipose tissue into the blood stream. Adiponectin counts for approximately $0.01 \%$ of the total plasma proteins. Hypoadiponectinemia, which refers to a low circulating level of adiponectin, was documented in obesity and its related diseases including insulin resistance, hyperglycemia and cardiovascular diseases [12-14]. Accumulating evidence showed that hypoadiponectinemia played a key role in 
the pathogenesis of obesity and related diseases [15-17]. Furthermore, adiponectin administration to obese or diabetic mice can reduce body weight and blood glucose levels while enhancing insulin sensitivity [18-20]. Based on these data, adiponectin was conceived to be a novel therapy target for obese and insulin resistance [21]. Elevation of adiponectin level by EGGG was documented in non-obese spontaneous diabetic rats and spontaneous hypertension rats [22,23]. Based on the above research, we hypothesized that GTPs might regulate the adiponectin levels in HF fed rats, through which GTPs exert their preventive effects on obesity and related diseases.

Adiponectin expression is regulated by factors such as peroxisome proliferator-activated receptor (PPAR) $\gamma$, CCAAT-enhancer-binding protein (C/EBP) $\alpha$, Kruppel-like factor 7 (KLF7), and sterol regulatory element binding protein-1c (SREBP-1c), Among these factors, PPAR $\gamma$ is recognized as the master regulator of adiponectin gene transcription. PPAR $\gamma$ binds directly to a functional PPAR-responsive element (PPRE) in adiponectin promoter, and increases the transcription of adiponectin gene [24]. Thiazolidinediones (TZDs), agonists of PPAR $\gamma$, stimulated gene expression and increased the plasma level of adiponectin in obese mice and obese people with insulin resistance [25]. Dominant negative mutant in PPAR $\gamma$ gene inhibited circulating adiponectin by 5 times [26]. Although the results were inconsistent, PPAR $\gamma$ expression was reported to change in obese or diabetic conditions. Park et al. and Inoue et al. reported PPAR $\gamma$ expression increased in skeletal muscle, liver or adipose tissue of obesity or diabetic subjects $[27,28]$. Another study showed that long term over-feeding induced obesity and decreased PPAR $\gamma$ expressions in skeletal muscle and VAT [29]. The mechanism of these contradictory results was not fully understood. Evidence showed erkl/2 activation was involved in regulation of PPAR $\gamma$ expressions in different tissues [30,31]. A MAP kinase site, which is confirmed to be phosphorylated by MAPKs, was identified on the NH2-terminal domain of PPAR $\gamma$, and phosphorylation on the site would repress the transcription activity of PPAR $\gamma$ then decrease the adiponectin level [32]. Increased phosphorylation of PPAR $\gamma$ was observed in obesity and insulin-resistant conditions, and the involvement of increased activation of erkl/2 was proposed [33]. Regulating effects of GTPs on the expression of PPAR $\gamma$ were reported though the results were not consistent [34]. Additionally, our previous study demonstrated GTPs would affect the MAPK signal pathways [35]. Based on these facts, we hypothesized that GTPs may regulate adiponectin levels via PPAR $\gamma$ by modulating erk1/2 activations.

In this study, male Wistar rats were fed on HF diet, and the effects of GTPs on body weight gain and adiponectin levels were observed. The signaling pathway mechanism was explored along with the regulatory roles of PPAR $\gamma$ and erk $1 / 2$.

\section{Materials and Methods}

\section{Ethics Statement}

This study was carried out in strict accordance with the guidelines and authorization for the use of laboratory animals. The protocol was approved by the Committee on the Ethics of Animal Experiments of the Huazhong University of Science and Technology (Permit number: S249). All efforts were made to minimize suffering.

\section{Reagents and Materials}

Anti- $\beta$ actin was from Santa Cruz Biotechnology, Inc. (Santa Cruz. CA. USA). Anti-erkl/2 and p-erk1/2 antibodies were purchased from Cell Signaling Technology (Billerica, MA, USA).
Anti-PPAR $\gamma$ antibody was purchased from Abcam (Cambridge, MA, USA); GTPs (purity $>98 \%$ ) were purchased from Fuzhou Rimian Inc. (Fuzhou, Fujian, China); TRIZOL was from Invitrogen Inc. (Carlsbad, CA, USA) and Real time quantitative PCR kit was purchased from TAKARA Bio Inc. (Otsu, Shiga, Japan); ELISA kits for adiponectin and insulin were purchased from R\&D Systems. (MN, USA). All other chemicals were of the highest grade commercially available.

\section{Animals}

After one week's acclimation, thirty male Wistar rats, weighting 40-60 g, were randomly divided into 5 groups. The control group was fed on standard chow; the other 4 groups were fed with modified HF chow containing $60 \%$ (w/w) standard chow, $12 \%$ lard, $12 \%$ sugar, $6 \%$ peanuts powder, $8 \%$ yolk powder, and $1 \%$ milk powder. Since the 4 th week, 3 of the $4 \mathrm{HF}$ groups started to drink water containing different concentrations of GTPs $(0.8,1.6$, $3.2 \mathrm{~g} / \mathrm{L})$. At the end of the $26^{\text {th }}$ week, all animals were sacrificed, tissues were snap frozen with liquid nitrogen then stored at $-80^{\circ} \mathrm{C}$ freezer. Blood biochemical indexes, adiponectin levels and insulin levels were tested. This study was carried out in strict accordance with the guidelines and authorization for the use of laboratory animals. The protocol was approved by the Committee on the Ethics of Animal Experiments of the Huazhong University of Science and Technology. All efforts were made to minimize suffering.

\section{VATs Culture}

Male Wistar rats were sacrificed and VATs were collected under asepsis condition. One hundred fifty $\mathrm{mg}$ VAT was maintained at $37^{\circ} \mathrm{C}$ in $5 \% \mathrm{CO}$. VATs cultured in DMEM with high glucose were treated without GTPs, with GTPs $(4 \mu \mathrm{g} / \mathrm{ml})$ for 48 hrs, or treated with PD98059 for 1 hour, respectively. VATs incubated with $5.5 \mathrm{mmol} / \mathrm{L}$ glucose in medium were used as control.

\section{Quantitative Real-time PCR}

Following the manufacturer's instructions, total RNA was extracted from fat tissue using TRIZOL then quantified by UV spectrophotometry. Samples with the A260/280 ratio lies between $1.8 \sim 2.0$ were used. Reverse transcription reaction (RT) was performed with $1 \mu \mathrm{g}$ total RNA from each sample using random primers. Real time PCR analysis was carried out using qPCR SYBR Green mix with the following parameters: 1 cycle, $95^{\circ} \mathrm{C}$, $5 \mathrm{~s} ; 40$ cycles, $95^{\circ} \mathrm{C} 10 \mathrm{~s} ; 57^{\circ} \mathrm{C}, 30 \mathrm{~s}$. Changes of gene expression were determined by the comparative $\mathrm{Ct}$ method with GADPH as reference. The primers used in the PCR were as follows: GADPH: glyceraldehyde-3-phosphate dehydrogenase (GAPDH) (BC059110) sense: CAG TGG CAG CGT CGT GTC AT, antisense: AGG GGC CAT CGA CAG TCT TC; Adiponectin (NM144744) sense: GGT GAC CAG GAG ATG CT, antisense: TAG GGT GAA TGG TGA GTG ATA; PPAR $\gamma$ (NM001145366) sense: TCA GGT TTG GGG GAA TG, antisense: TTT GGT CAG CGG GAA GG.

\section{Enzyme-linked Immunosorbent Assay}

To assess adiponectin secretion and circulating insulin, the blood of the rats was collected and serum was separated by centrifugation, and the culture supernatant of fat explants was harvested and centrifuged to remove impurities. Adiponectin and insulin concentrations were measured using an enzyme-linked immunosorbent assay according to the manufacturer's instruction. 
A

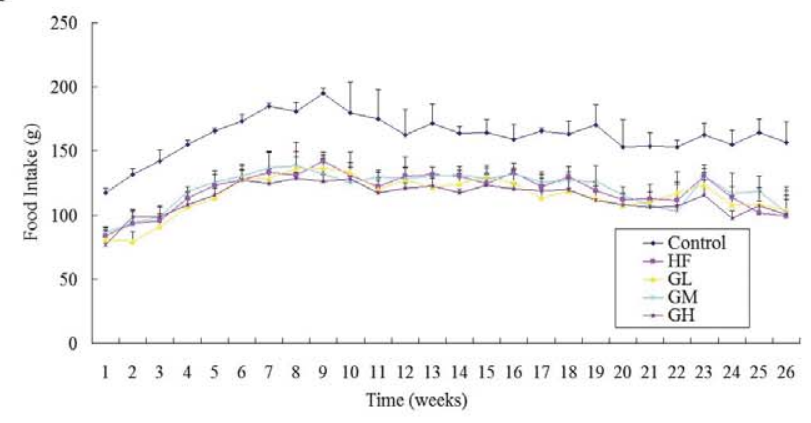

$\mathrm{C}$

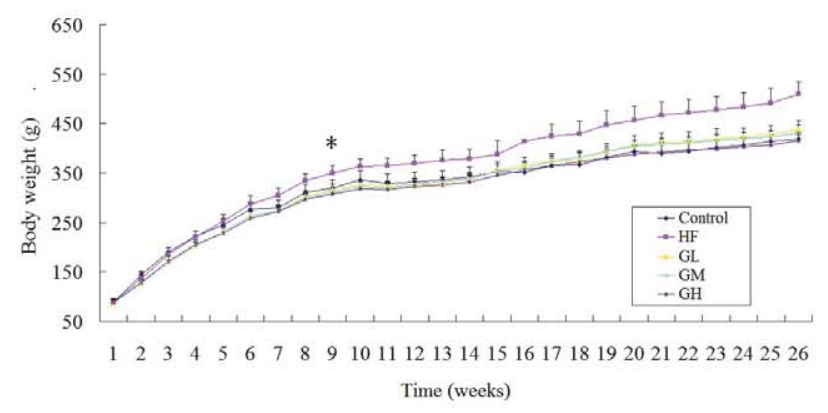

$\mathrm{E}$

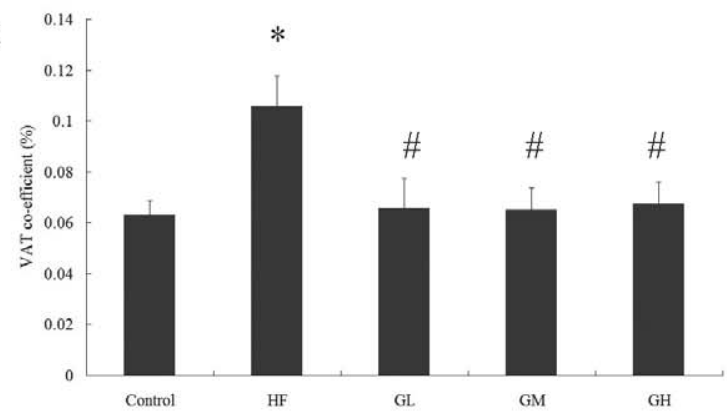

B

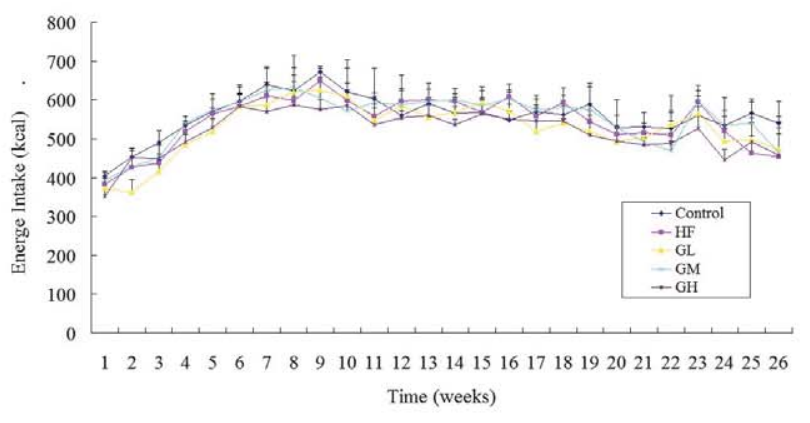

D

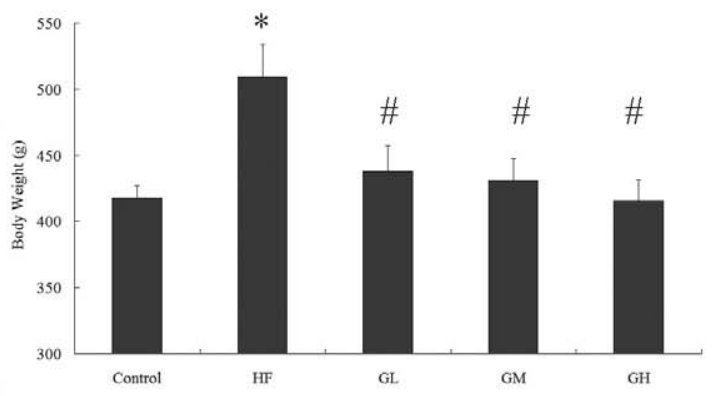

Figure 1. GTPs reduced body weight gain and VAT coefficient induced by HF diet without affecting the energy intake. GTPs treatment did not affect the energy intake in compare with the HF group, although the food intake of the control group is higher than other groups(A), no significant difference was observed in energy intake (B). Difference in body weight started from the $9^{\text {th }}$ week (C). The body weight was obviously higher in the HF group in compare with all other groups (D); VAT coefficient of the HF group was obviously higher than the control group, and GTPs treatment alleviated the effect (E). ( ${ }^{*} P<0.05$ vs. the control; \# $P<0.05$ vs. the HF group). Data is expressed as the mean \pm SEM ( $\left.N=6\right)$. doi:10.1371/journal.pone.0053796.g001

Table 1. GTPs downregulated the blood glucose and improved the lipid profile in HF fed rats.

\begin{tabular}{llllll}
\hline & & & & & \\
\hline & Control & HF & GL & GM & GH \\
\hline Blood Glucose(mmol/L) & $5.55 \pm 0.48$ & $6.42 \pm 0.16^{*}$ & $5.96 \pm 0.40^{*} \#$ & $5.93 \pm 0.41^{*} \#$ & $5.40 \pm 0.46^{*} \#$ \\
Insulin $(\mathrm{ng} / \mathrm{mL})$ & $11.47 \pm 0.81$ & $14.73 \pm 0.58^{*}$ & $13.97 \pm 1.11^{*}$ & $14.53 \pm 1.70^{*}$ & $14.13 \pm 0.88^{*}$ \\
Homa-IR & $2.71 \pm 0.07$ & $4.16 \pm 0.10^{*}$ & $3.59 \pm 0.19^{*} \#$ & $3.58 \pm 0.24^{*} \#$ & $3.27 \pm 0.11^{*} \#$ \\
TC(mmol/L) & $1.06 \pm 0.10$ & $1.46 \pm 0.04^{*}$ & $1.38 \pm 0.13^{*}$ & $1.06 \pm 0.16 \#$ & $0.73 \pm 0.12^{*} \#$ \\
TG(mmol/L) & $0.51 \pm 0.07$ & $0.73 \pm 0.14^{*}$ & $0.64 \pm 0.10^{*}$ & $0.65 \pm 0.10^{*}$ & $0.43 \pm 0.12 \#$ \\
LDL-C/HDL-C & $0.53 \pm 0.02$ & $1.86 \pm 0.29^{*}$ & $1.48 \pm 0.08^{*} \#$ & $0.65 \pm 0.05 \#$ & $0.31 \pm 0.08^{*} \#$ \\
\hline
\end{tabular}

${ }^{*} P<0.05$ vs. the control;

${ }^{\#} P<0.05$ vs. the HF group.

doi:10.1371/journal.pone.0053796.t001 
A

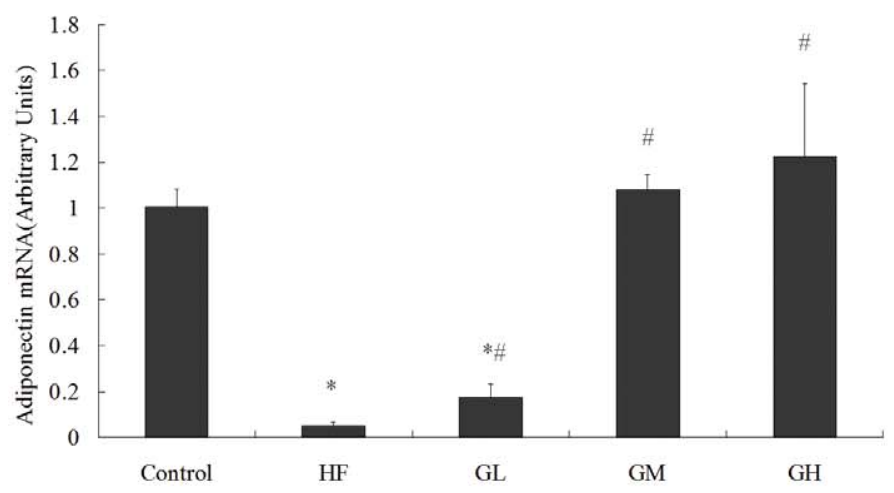

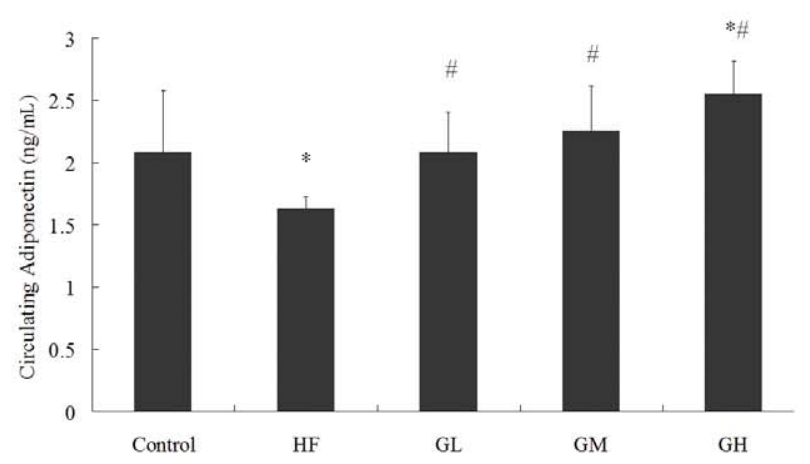

Figure 2. GTPs alleviates the decrease of adiponectin expression in fat tissue and serum induced by HF diet. Fig. 2 A showed the mRNA level of adiponectin in adipose tissue, the result is presented in arbitrary units using GADPH as reference. Fig. 2 B presented the levels of serum adiponectin. The HF group exhibited significantly reduced $\mathrm{mRNA}$ and circulating levels of adiponectin, the decreased expressions were attenuated by GTPs treatment at different concentrations (GL $0.8 \mathrm{~g} / \mathrm{L}, \mathrm{GM} 1.6 \mathrm{~g} / \mathrm{L}, \mathrm{GH} 3.2 \mathrm{~g} / \mathrm{L}$.) (* P<0.05 vs. the control; \# P<.05 vs. the HF group). Data is expressed as Mean $\pm \mathrm{SEM}(\mathrm{N}=6)$.

doi:10.1371/journal.pone.0053796.g002

Measurements were performed in six replicates. Results were presented as $\mathrm{ng} / \mathrm{mL}$.

\section{Electrophoresis and Immunoblotting}

Fat tissue were homogenized and then lysed in the extraction buffer containing $50 \mathrm{mmol} / \mathrm{L}$ Tris/HCl $(\mathrm{pH} 8.0), 150 \mathrm{mmol} / \mathrm{L}$ $\mathrm{NaCl}, 1 \%$ Nonidet-P40, 1\% sodium deoxycholate, $0.1 \%$ sodium dodecyl sulfate (SDS), $0.1 \mathrm{mmol} / \mathrm{L}$ DTT, $0.05 \mathrm{mmol} / \mathrm{L} \mathrm{PMSF}$, $0.002 \mathrm{mg} / \mathrm{ml}$ aprotinin, $0.002 \mathrm{mg} / \mathrm{ml} \mathrm{leupeptin,} \mathrm{and} 1 \mathrm{mmol} / \mathrm{L}$ NaVO3 [36]. The protein concentration was quantified with BIORAD DC Protein Assay Reagent (Bio-Rad, Hercules, CA, USA). Sodium dodecyl sulfate-polyacrylamide gel electrophoresis and immunological blotting was performed according to the method of Amersham Biosciences. Protein expression was visualized with a chemiluminescent detection system (Syngen, Cambridge, UK) and analyzed by Gel Pro 3.0 software (Biometra, Goettingen, Germany).

\section{Statistical Analysis}

All quantitative data are presented as Mean \pm S.E. Data were compared by ANOVA-SNK or Dunnett's T3 test. Differences were considered significant when $P<0.05$.

\section{Results}

1. GTPs Reduced Body Weight Gain and VAT Coefficient without Affecting the Food Intake

As shown in fig. 1, GTPs treatment did not affect the energy intake in comparison to the HF group, although the food intake of the control group was higher than other groups, no significant difference was observed in energy intake due to the different energy densities of normal and $\mathrm{HF} \operatorname{diet}(\mathrm{A}, \mathrm{B})$. Difference in body weight gain started from the $9^{\text {th }}$ week $(\mathrm{C})$. At the end of the experiment, the body weight and VAT coefficient were obviously higher in the HF group; the effects were ameliorated by GTPs treatment $(\mathrm{D}, \mathrm{E})$. GTPs treatment also reduced the blood glucose and HOMA-IR index and reversed the lipid profile change in HF fed rats (Table 1). However, GTPs treatment did not affect the circulating insulin level compared to the HF group.
2. GTPs Relieved the Down-expression of Adiponectin in VAT and Serum Induced by HF Diet

To assess the adiponectin expression and secretion, adiponectin mRNA in VAT was tested by qRT-PCR, and serum adiponectin was tested by ELISA. Fig. 2 demonstrated that HF fed rats exhibited lower expressions of adiponectin at transcriptional and phenotypic levels, while treatment of GTPs alleviated the adiponectin-reducing effect of $\mathrm{HF}$ diet.

3. GTPs Attenuated the Down-expression of PPAR $\gamma$, the Increased Phosphorylation of PPAR $\gamma$, and the Increased Phosphorylation of erk1/2 in VAT Induced by HF Diet

Researches demonstrated that adiponectin is a downstream target gene of PPAR $\gamma$ [13] while p-PPAR $\gamma$ preserves an inhibitory effect on adiponectin expression [20]. The mRNA of PPAR $\gamma$ and protein expression of PPAR $\gamma$ and p-PPAR $\gamma$ were tested by qRTPCR and Western Blot, respectively. As shown in Fig. 3, both the mRNA expression (A) and protein expression (B) of PPAR $\gamma$ decreased in HF group while phosphorylation of $\operatorname{PPAR} \gamma(\mathrm{C})$ increased in HF fed group, and these changes were attenuated by GTPs treatment. Increased phosphorylation of erk $1 / 2$ induced by HF diet was also ameliorated by GTPs treatment (D).

\section{GTPs or Selective Inhibitor of erk1/2 Relieved High Glucose-induced Adiponectin Decrease}

Fig. 4 showed adiponectin's mRNA level in cultured VAT (A) and its secretion in culture supernatant (B). High glucose downregulated the mRNA expression in VATs and the secreted amount in culture medium. Both GTPs co-incubation and treatment with PD98059 alleviated the adiponectin-reducing effect of high glucose.

\section{GTPs and Selective Inhibitor of erk $1 / 2$ Relieved the Down-expression of PPAR $\gamma$ and the Increased Phosphorylation of PPAR $\gamma$ and erk $1 / 2$ in Cultured VAT}

As shown in Fig. 5, both mRNA (A) and protein expressions (B) were down-regulated by high glucose incubation in cultured VATs. GTPs treatment diminished the PPAR $\gamma$-reducing effect of high glucose incubation, and inhibition of erk1/2 by PD98059 exerted similar effects. Both GTPs and PD98059 treatments 
A

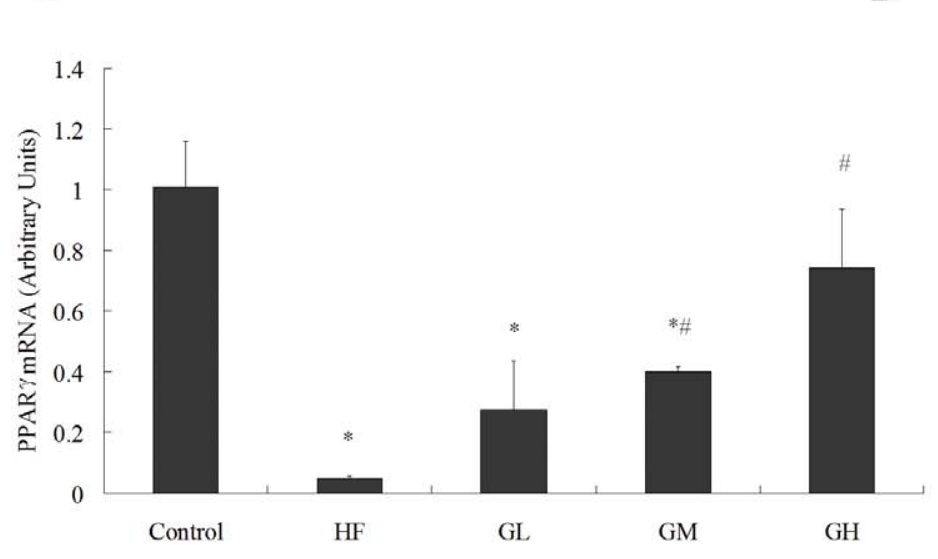

B

$\operatorname{PPAR} \gamma$
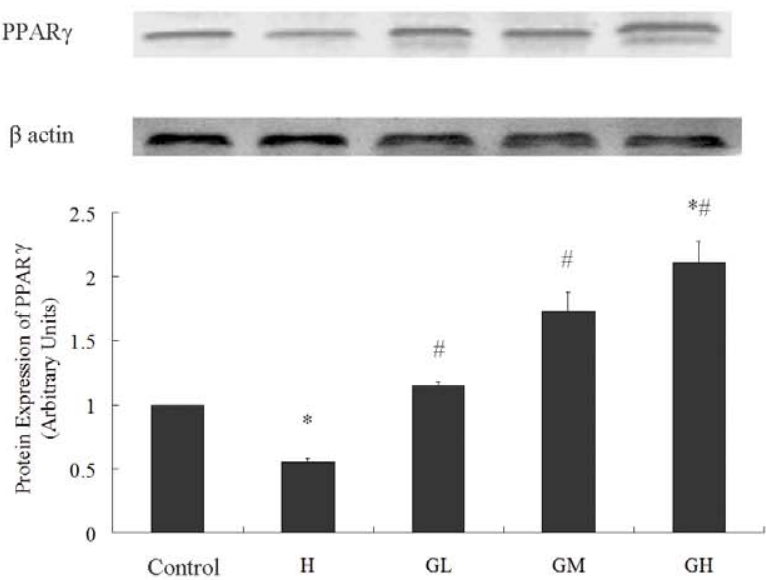

$\mathrm{C}$

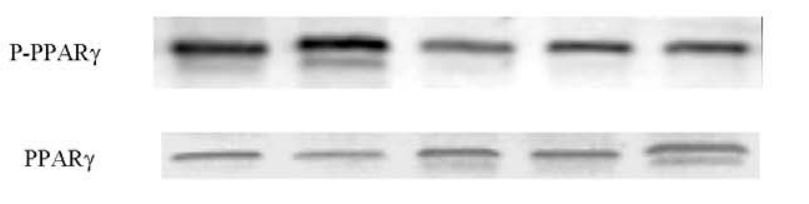

$\mathrm{D}$
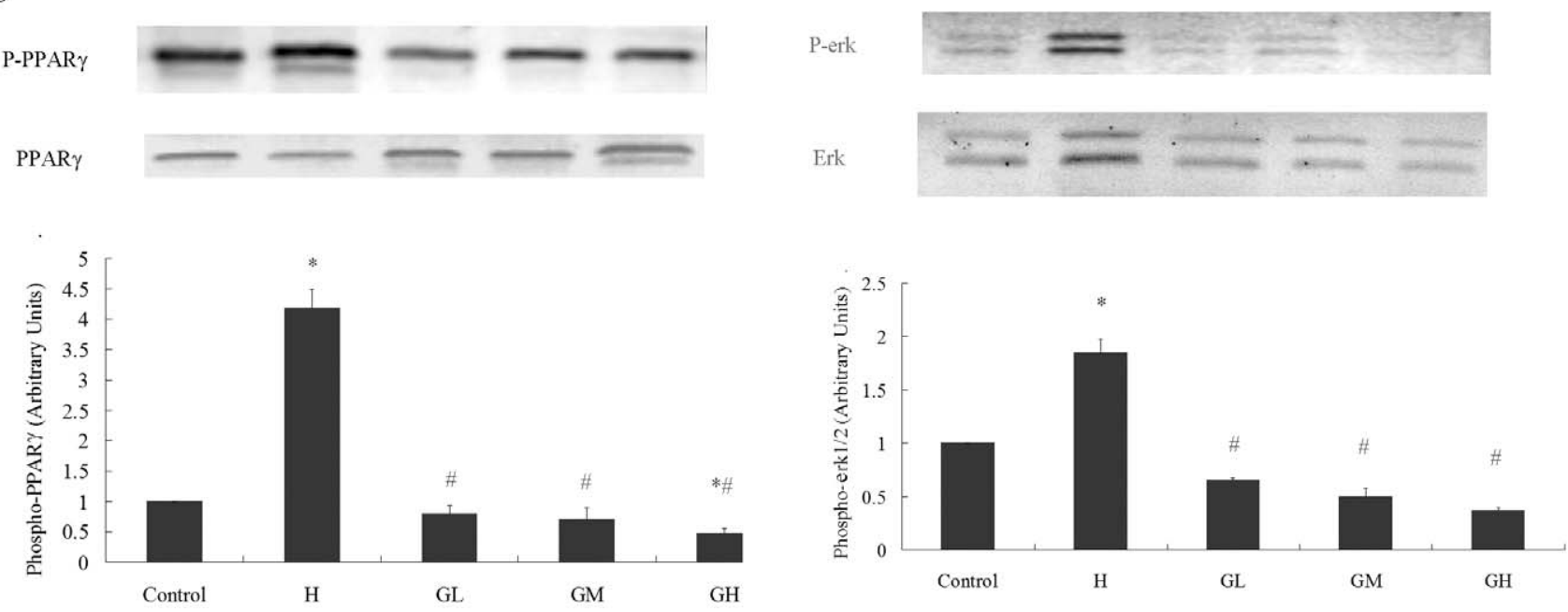

Figure 3. GTPs attenuated the phosphorylation, decreased expression of PPAR $\gamma$ and erk1/2 activation in fat tissue induced by HF diet. PPAR $\gamma$ mRNA level was calculated with GADPH as reference. Protein expression and phosphorylation of PPAR $\gamma$ and erk1/2 were tested by western blot; the results were presented in arbitrary units using beta-actin, PPAR $\gamma$ and erk $1 / 2$ as references, respectively. The value of the control group was considered as 1.00. HF down-regulated the mRNA $(A, N=6)$ and protein expression $(B, N=3)$ of PPAR $\gamma$ while up-regulated the phosphorylation of PPAR $\gamma(C, N=3)$ and erk $1 / 2(D, N=3)$, the effects could be ameliorated by GTPs treatment. ${ }^{*} P<0.05$ vs. the control; \# P<0.05 vs. the HF group). Data is expressed as Mean \pm SEM.

doi:10.1371/journal.pone.0053796.g003

attenuated the elevated phosphorylation of $\operatorname{PPAR} \gamma(\mathrm{C})$ and erk $1 / 2$ (D) in high glucose incubated group.

\section{Discussion}

The present work demonstrated that GTPs alleviated VAT deposit and hypoadiponectinemia in HF fed rats. Meanwhile, GTPs up-regulated the expression while down-regulating the phosphorylation of $\operatorname{PPAR} \gamma$, the principal regulator of adiponectin. GTPs also inhibited the over-activation of erk $1 / 2$ induced by HF diet. Similar results were observed in high glucose incubated VAT, co-treated with GTPs in vitro. Like being treated with GTPs, selective inhibition of erkl/2 alleviated the down-expression of adiponectin, down-regulated phosphorylation of PPAR $\gamma$, and upregulated the expression of PPAR $\gamma$ induced by high glucose incubation.

Adiponectin was demonstrated to be adversely associated with obesity, insulin resistance, cardiovascular diseases, and obesity related fatty liver disease $[37,38]$. The production of adiponectin was reported to be related to visceral fat deposits [39]. Hypoadiponectinemia was observed in obese humans [40] and obese animal models in the present study, while increased adiponectin levels was observed after weight loss [41]. Genetic studies showed that adiponectin polymorphism, SNPs $45 \mathrm{~T}$ to $\mathrm{G}$ and $276 \mathrm{G}$ to $\mathrm{T}$ are related to obesity in humans [42] and the G/G genotype for SNP276 was associated with lower serum adiponectin levels and waist-to-hip ratio [43], novel genetic determinents of adiponectin levels were identified in 2012 and the identified loci were proved to impact upon metabolic diseases [44]. Furthermore, intravenous or intra-cerebro-ventricular administration of adiponectin decreased body weight [2,45]. Diet composition and exercise, which are closely related to body weight, were showed to affect plasma adiponectin levels. Reports demonstrated that HF diet decreased adiponectin levels [46,47], which is consistent with the present study. While low fat, high carbohydrate diet [48], diets 
A.

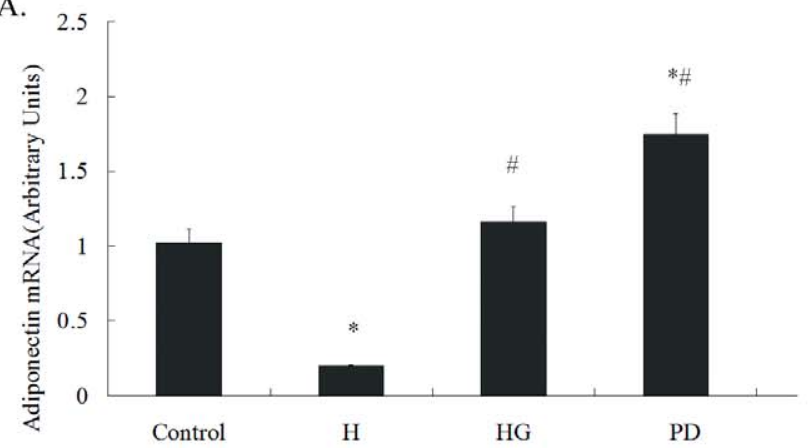

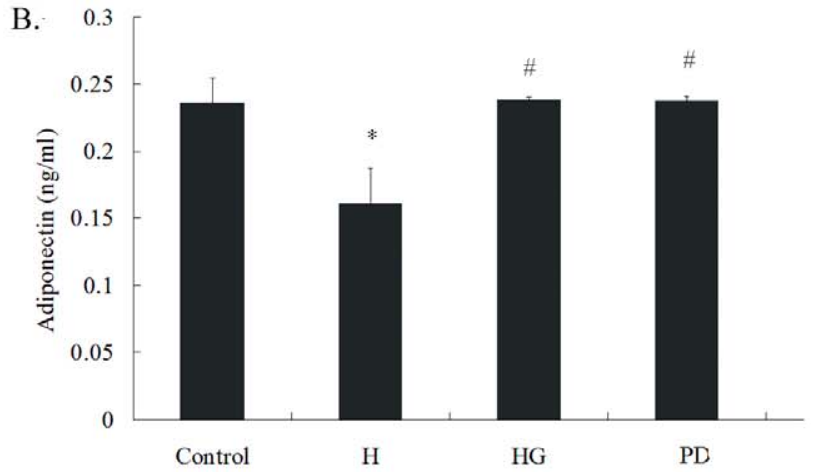

Figure 4. GTPs and selective inhibitor of erk1/2 alleviated high glucose-induced adiponectin decrease. One hundred fifty mg VAT were cultured in DMEM with high glucose $(33 \mathrm{mmol} / \mathrm{L})$ and cotreated with GTPs $(4 \mu \mathrm{g} / \mathrm{ml})$ for $48 \mathrm{hrs}$ or pretreated with PD98059 for $1 \mathrm{hr}$. The supernatant of cell culture medium was collected for ELISA of secreted adiponectin. (A) The mRNA level of adiponectin, comparative Ct method with GADPH as reference was adopted. (B) The secreted adiponectin in the supernatant of culture medium is in $\mathrm{ng} / \mathrm{mL}$. High glucose incubation $(\mathrm{H})$ down-regulated the mRNA expression and secretion of adiponectin, the effects could be attenuated by GTPs treatment (GH) or PD98059(PD). (* P<0.05 vs. the control; \# $\mathrm{P}<0.05$ vs. the HG group). Data is expressed as Mean \pm SEM $(N=6)$.

doi:10.1371/journal.pone.0053796.g004

low in glycemic load and high in fiber [49], and food restriction $[50,51]$ increased adiponectin levels. Exercise was demonstrated to increase adiponectin levels in humans and animals [52,53]. These reports suggested that food composition or exercise affect body weight via regulating adiponectin. Therefore, means to increase adiponectin level was conceived to be a novel therapy strategy for obesity and related diseases [2]. Similar to adiponectin, GTPs consumption was reported be associated with obesity, metabolic syndrome, type 2 diabetes and cardiovascular diseases [2]. In this study, GTPs treatment alleviated VATs increase and blood glucose elevation, and improved the insulin sensitivity and lipid profile in the HF fed rats. At the same time, GTPs treatment attenuated the decrease of adiponectin induced by $\mathrm{HF}$ or high glucose, which was also obeserved in another research using tea extracts [54]. From this point, regulation of adiponectin should be related to the mechanism by which GTPs exert anti-obesity, antidiabetic and cardiovascular protective effects. However, further studies to investigate the effects of GTPs on adiponectin knockout mice would help consolidating the conclusion.

Gene expression of adiponectin is mainly regulated by nuclear transcriptor named PPAR $\gamma$ PPAR $\gamma$ binds with PPRE element in the adiponectin gene and stimulates the transcription [13]. Research demonstrated PPAR $\gamma$ agonists would increase the circulating adiponectin in a metabolic syndrome rat model [55], and an epidemiological study proved that PPAR $\gamma$ gene polymorphism would affect the serum adiponectin levels [56]. PPAR $\gamma$ expression reduction was observed in obesity subjects $[57,58]$. In our experiments, decreased mRNA and protein expressions of $\operatorname{PPAR} \gamma$ and adiponectin were observed in HF fed rats and high glucose incubated VATs, and these effects could be attenuated by GTPs treatment. The transcription activity of PPAR $\gamma$ was demonstrated to be affected by several factors, including phosphorylation or sumoylation of the receptor $[59,60]$ and recruitment of different cofactors [61], among which phosphorylation of PPAR $\gamma$ is investigated most. Phosphoryltion of PPAR $\gamma$ resulted in decreased PPAR $\gamma$ activation followed by downregulation of adiponectin gene [2]. Genetic techniques of inhibiting PPAR $\gamma$ 's phosphorylation could improve insulin resistance and increase adiponectin level [62]. Along with the decrease of adiponectin expression, increased phosphorylation of PPAR $\gamma$ was observed in vitro and in vivo in the present study, and all these effects could be attenuated by GTPs treatment. Meanwhile, phosphorylation of PPAR gamma would prime PPAR $\gamma$ for polyubiquitination and proteasomal degradation, increase the sumoylation of $\mathrm{K} 77 / \mathrm{K} 107$ in a lysine motif IKVE directly adjacent to S82/112, and then synergistically repress $\operatorname{PPAR} \gamma$ transactivation [63]. Activation of erk1/2, which was documented in adipocytes of obese rodents and humans [64], was confirmed to induce phosphorylation of PPAR $\gamma$ [65]. In the present study, HF diet and high glucose incubation elevated erkl/2 activation and phosphorylation of $\operatorname{PPAR} \gamma$, which was consistent with the study conducted by Hosooka et al [66]. Treatment with GTPs inhibited the activation of erkl/2, and alleviated the decreased PPAR $\gamma$ expression and increased PPAR $\gamma$ phosphorylation induced by HF diet in vivo or by high glucose incubation in vitro. Selective inhibition of erk1/2 by PD98059 exerts same effects as GTPs treatment. These results suggested that GTPs increased PPAR $\gamma$ expression and inhibited PPAR $\gamma$ phosphorylation by downregulating erkl/2 in $\mathrm{HF}$ fed rats or under high glucose condition. However, the regulatory roles of erkl/2 activation played on PPAR $\gamma$ expression remain uncertain. Erk1/2 might directly downregulate the PPAR $\gamma$ expression, as well as reduce PPAR $\gamma$ expression by triggering the phosphorylation of PPAR $\gamma$.

\section{Conclusion}

GTPs prevent HF-induced obesity by up-regulating adiponectin levels. The underlying mechanisms may include the inhibition of erk1/2 activation, alleviation of PPAR $\gamma$ phosphorylation, and increase of the PPAR $\gamma$ expression. Further research to track the $\operatorname{PPAR} \gamma$ and adiponectin level along with the pathogenesis of obesity would lead to better understanding of the mechanism.

\section{Acknowledgments}

Thanks are due to all the members in our academic group for helping us complete the experiments and School of Public Health for providing us good environmental condition. Our special thanks goes to Hongmei and Ryan for revising the manuscript.

\section{Author Contributions}

Conceived and designed the experiments: CT XY RZ CY. Performed the experiments: CT RZ CY SD DL XJ JL WR. Analyzed the data: GT XY HW. Contributed reagents/materials/analysis tools: CY SX. Wrote the paper: CT CY HW SX. 
PPAR $\gamma$

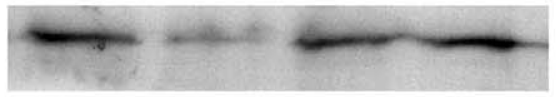

$\beta$ actin
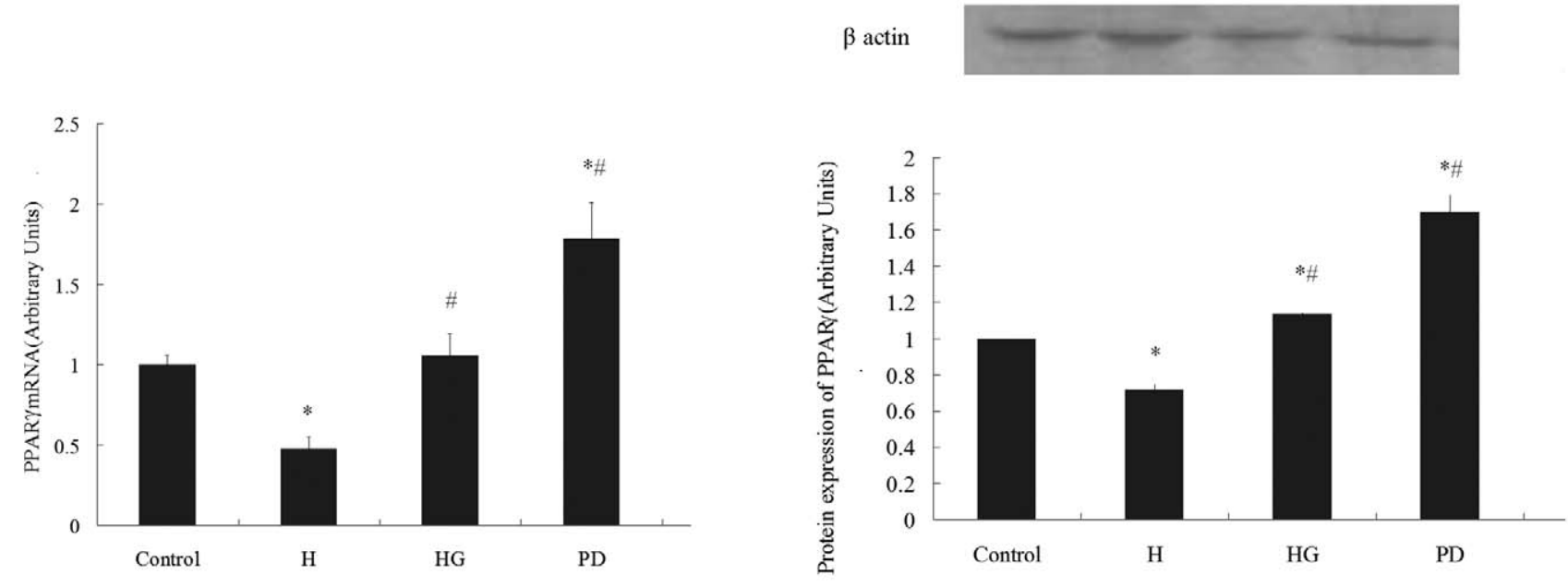

P-PPAR $\gamma$
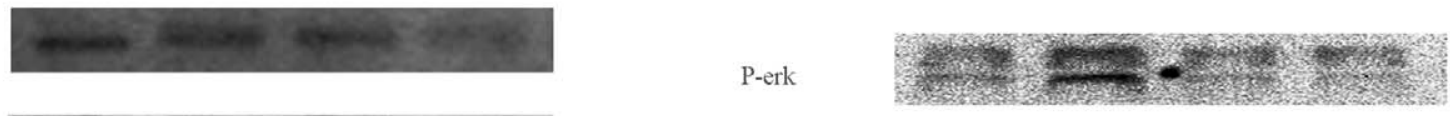

$\operatorname{PPAR} \gamma$
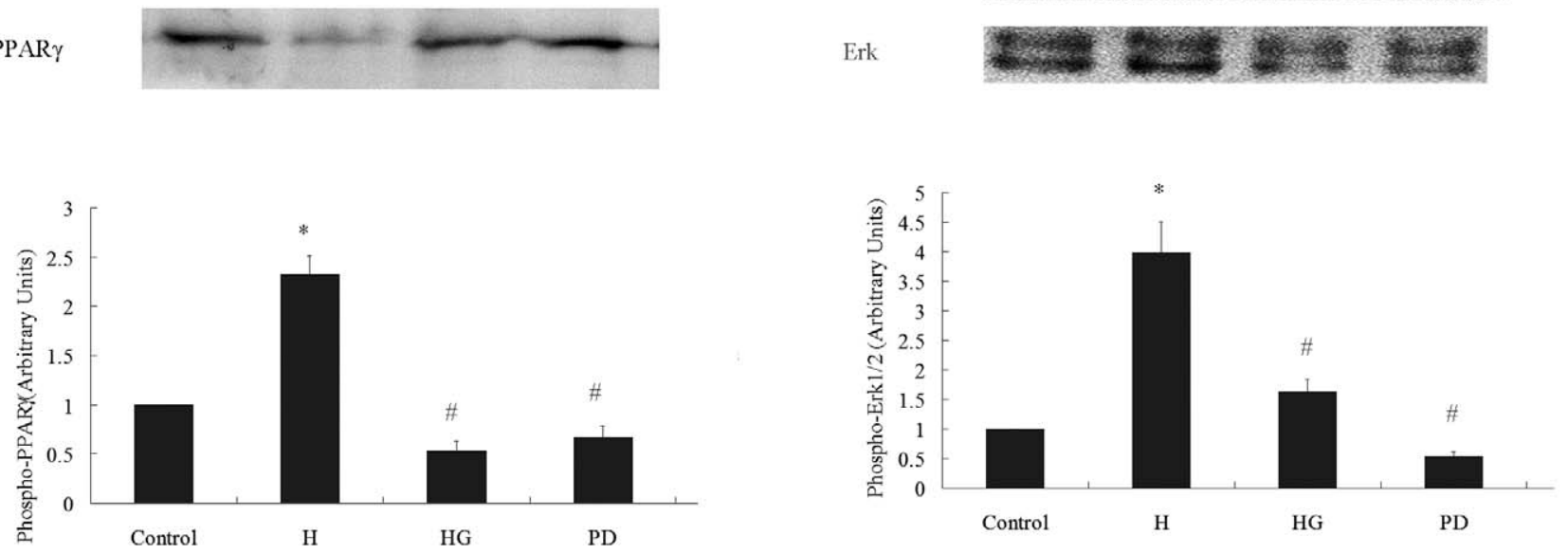

Figure 5. Inhibition of erk1/2 and GTPs treatment attenuated the phosphorylation and down-expression of PPAR $\gamma$ and erk $1 / 2$ activation in cultured VAT under high glucose condition. The cultured VAT explants were treated with GTPs and PD98059, respectively. High glucose incubation down-regulated the PPAR $\gamma$ mRNA $(A, N=6)$ and protein expression $(B, N=3)$ while up-regulated the phosphorylation of PPAR $\gamma(C$, $\mathrm{N}=3$ ) and phosphorylation of erk $1 / 2(\mathrm{D}, \mathrm{N}=3)$, all the above effects could be attenuated by GTPs or PD98059. $\left({ }^{*} \mathrm{P}<0.05\right.$ vs. the control; \# $\mathrm{P}<0.05$ vs. the HG group). Data is expressed as Mean \pm SEM.

doi:10.1371/journal.pone.0053796.g005

\section{References}

1. Asia Pacific Cohort Studies Collaboration (2007)The burden of overweight and obesity in the Asia-Pacific region.Obes Rev 8(3): 191-196.

2. Pories WJ (2008) Bariatric surgery: risks and rewards. J Clin Endocrinol Metab 93: S89-96.

3. Filippatos TD, Derdemezis CS, Gazi IF, Nakou ES, Mikhailidis DP, et al. (2008) Orlistat-associated adverse effects and drug interactions: a critical review. Drug Saf 31: 53-65.

4. Zaveri NT (2006) Green tea and its polyphenolic catechins: medicinal uses in cancer and noncancer applications. Life Sci 78(18): 2073-2080.

5. Kuriyama S, Shimazu T, Ohmori K, Kikuchi N, Nakaya N, et al. (2006) Green tea consumption and mortality due to cardiovascular disease, cancer, and all causes in Japan: the Ohsaki study. JAMA 296(10): 1255-1265.

6. Wolfram S, Wang Y, Thielecke F (2006) Anti-obesity effects of green tea: from bedside to bench. Mol Nutr Food Res 50: 176-187.
7. Bose M, Lambert JD, Ju J, Reuhl KR, Shapses SA, et al. (2008) The major green tea polyphenol, (-)-epigallocatechin-3-gallate, inhibits obesity, metabolic syndrome, and fatty liver disease in high-fat-fed mice. J Nutr 138: 1677-1683.

8. Wolfram S, Raederstorff D, Wang Y, Teixeira SR, Elste V, et al. (2005) TEAVIGO (epigallocatechin gallate) supplementation prevents obesity in rodents by reducing adipose tissue mass. Ann Nutr Metab 49: 54-63.

9. Nagao T, Komine Y, Soga S, Meguro S, Hase T, et al. (2005) Ingestion of a tea rich in catechins leads to a reduction in body fat and malondialdehyde-modified LDL in men. Am J Clin Nutr 81: 122-129.

10. Nagao T, Hase T, Tokimitsu I (2007) A green tea extract high in catechins reduces body fat and cardiovascular risks in humans. Obesity (Silver Spring) 15: 1473-1483. 
11. Nagao T, Meguro S, Hase T, Otsuka K, Komikado M, et al. (2009) A catechinrich beverage improves obesity and blood glucose control in patients with type 2 diabetes. Obesity (Silver Spring) 17: 310-317.

12. Hotta K, Funahashi T, Arita Y, Takahashi M, Matuda M, et al. (2001) Plasama concentration of a novel, adipose-specific protein, adiponectin, in type 2 diabetic patients. J Clic Endocrinol Metab. 86: 1930-1935.

13. Oberthuer A, Dönmez F, Oberhäuser F, Hahn M, Hoppenz M, et al. (2012) Hypoadiponectinemia in extremely low gestational age newborns with severe hyperglycemia - a matched-paired analysis. PLoS One 7(6): e38481.

14. Kumada M, Kihara S, Sumitsuji S, Kawamoto T, Matsumoto S, et al. (2003) Association of hypoadiponectinemia with coronary artery disease in men. Arterioscler Thromb Vasc Biol 23(1): 85-89.

15. Renaldi O, Pramono B, Sinorita H, Purnomo LB, Asdie RH, et al. (2009) Hypoadiponectinemia: a risk factor for metabolic syndrome. Acta Med Indones 41(1): $20-24$

16. Lara-Castro C, Fu Y, Chung BH, Garvey WT (2007) Adiponectin and the metabolic syndrome: mechanisms mediating risk for metabolic and cardiovascular disease. Curr. Opin. Lipidol 18 (3): 263-270.

17. Diez JJ, Iglesias P (2003) The role of the novel adipocyte-derived hormone adiponectin in human disease. Eur J Endocrinol 148(3): 293-300.

18. Fruebis J, Tsao TS, Javorschi S, Ebbets-Reed D, Erickson MR, et al. (2001) Proteolytic cleavage product of $30-\mathrm{kDa}$ adipocyte complement-related protein increases fatty acid oxidation in muscle and causes weight loss in mice. Proc Natl Acad Sci U S A 98(4): 2005-2010.

19. Combs TP, Berg AH, Obici S, Scherer PE, Rossetti L (2001) Endogenous glucose production is inhibited by the adipose-derived protein Acrp30. J Clin Invest 108: 1875-1881

20. Yamauchi T, Kamon J, Waki H, Terauchi Y, Kubota N, et al. (2001) The fatderived hormone adiponectin reverses insulin resistance associated with both lipoatrophy and obesity. Nat Med 7(8): 941-946.

21. DeGlercq V, Stringer D, Hunt R, Taylor GG, Zahradka P (2011) Adipokine Production by Adipose Tissue: A novel target for treating metabolic syndrome and its sequelae. In: Wang M (ed). Metabolic Syndrome: Underlying mechanisms and drug therapies. John Wiley \& Sons, Inc.: Hoboken, NJ. 73 131.

22. Shimada M, Mochizuki K, Sakurai N, Goda T (2007) Dietary supplementation with epigallocatechin gallate elevates levels of circulating adiponectin in nonobese type-2 diabetic Goto-Kakizaki rats. Biosci Biotechnol Biochem 71(8): 2079-2082.

23. Potenza MA, Marasciulo FL, Tarquinio M, Tiravanti E, Colantuono G, et al. (2007) EGCG, a green tea polyphenol, improves endothelial function and insulin sensitivity, reduces blood pressure, and protects against myocardial I/R injury in SHR. Am J Physiol Endocrinol Metab 292(5): E1378-1387.

24. Iwaki M, Matsuda M, Maeda N, Funahashi T, Matsuzawa Y, et al. (2003) Induction of adiponectin, a fat-derived antidiabetic and antiatherogenic factor, by nuclear receptors. Diabetes 52(7): 1655-1663.

25. Yang WS, Jeng CY, Wu TJ, Tanaka S, Funahashi T, et al. (2002) Synthetic peroxisome proliferation activated receptor $\gamma$ agonist, rosiglitone, increase plasma levels of adiponectin in type 2 diabetes patients. Diabetes Care 25 (2): 376-380.

26. Combs TP, Wagner JA, Berger J, Doebber T, Wang WJ, et al. (2002) Induction of adipocyte complement related protein of 30 kilodaltons by PPAR $\gamma$ agonists: a potential mechanism of insulin sensitization 143 (3) : 998-1 007.

27. Park KS, Ciaraldi TP, Abrams-Carter L, Mudaliar S, Nikoulina SE, et al. (1997) PPAR-gamma gene expression is elevated in skeletal muscle of obese and type II diabetic subjects. Diabetes 46, 1230-1234.

28. Inoue M, Ohtake T, Motomura W, Takahashi N, Hosoki Y, et al. (2005) Increased expression of PPARgamma in high fat diet-induced liver steatosis in mice.Biochem Biophys Res Commun 336(1): 215-222.

29. Gayet C, Lerayl V, Saito M, Siliart B, Nguyen P (2007) The effects of obesityassociated insulin resistance on mRNA expression of peroxisome proliferatoractivated receptor-g target genes, in dogs. British Journal of Nutrition 98: 497503.

30. Liu LR, Lin SP, Chen CC, Chen YJ, Tai CC, et al. (2011) Serum Amyloid A Induces Lipolysis by Downregulating Perilipin Through ERK1/2 and PKA Signaling Pathways. Obesity 19: 2301-2309.

31. Kaplan JM, Hake PW, Denenberg A, Nowell M, Piraino G, et al. (2010) Phosphorylation of Extracellular Signal-Regulated Kinase(ERK)-1/2 Is Associated with the Downregulation of Peroxisome Proliferator-Activated Receptor (PPAR)- $\gamma$ during Polymicrobial Sepsis. MOL MED 16(11-12)491-497.

32. Adams M, Reginato MJ, Shao D, Lazar MA, Chatterjee VK (1997) Transcriptional Activation by Peroxisome Proliferator-activated Receptor g Is Inhibited by Phosphorylation at a Consensus Mitogen-activated Protein Kinase Site. J Bio Chem 272(8): 5128-5132.

33. Hosooka T, Noguchi T, Kotani K, Nakamura T, Sakaue H, et al. (2008) Dokl mediates high-fat diet-induced adipocyte hypertrophy and obesity through modulation of PPAR- $\gamma$ phosphorylation. Nature Medicine 14: 188-193.

34. Serisier S, Leray V, Poudroux W, Magot P, Ouguerram K, et al. (2008) Effects of green tea on insulin sensitivity, lipid profile and expression of PPARa and PPARg and their target genes in obese dogs.British Journal of Nutrition 99: 1208-1216.

35. Li Y, Ying C, Zuo X, Yi H, Yi W, et al. (2009) Green tea polyphenols downregulate caveolin-1 expression via ERK1/2 and p38MAPK in endothelial cells. J Nutr. Biochem 20(12): 1021-1027.
36. Ying CJ, Xu JW, Ikeda K, Takahashi K, Nara Y, et al. (2003) Tea polyphenols regulate nicotinamide adenine dinucleotide phosphate oxidase subunit expression and ameliorate angiotensin II-induced hyperpermeability in endothelial cells. Hypertens Res 26(10): 823-828.

37. Matsuzawa Y (2010) Adiponectin: a key player in obesity related disorders.Curr Pharm Des 16(17): 1896-1901.

38. Buechler C, Wanninger J, Neumeier M (2011) Adiponectin, a key adipokine in obesity related liver diseases.World J Gastroenterol 17(23): 2801-2811.

39. Yatagaia T, Nagasaka S, Taniguchib A, Fukushimac M, Nakamuraa T, et al. (2003) Hypoadiponectinemia is associated with visceral fat accumulation and insulin resistance in Japanese men with type 2 diabetes mellitus. Metabolism 52(10): 1274-1278.

40. Weyer C, Funahashi T, Tanaka S, Hotta K, Matsuzawa Y, et al. (2001) Hypoadiponectinemia in obesity and type 2 diabetes: close association with insulin resistance and hyperinsulinemia. J Clin Endocrinol Metab 86(5): 19301935.

41. Milan G, Granzotto M, Scarda A, Calcagno A, Pagano C, et al. (2002) Resistin and adiponectin expression in visceral fat of obese rats: effect of weight loss.Obes Res 10(11): 1095-1103.

42. Panagopoulou P, Stamna E, Tsolkas G, Galli-Tsinopoulou A, Pavlitou-Tsiontsi E, et al. (2009) Adiponectin gene polymorphisms in obese Greek youth. Pediatr Endocrinol Metab 22(10): 955-959.

43. González-Sánchez JL, Zabena CA, Martínez-Larrad MT, Fernández-Pérez C, Pérez-Barba M, et al. (2005) An SNP in the adiponectin gene is associated with decreased serum adiponectin levels and risk for impaired glucose tolerance.Obes Res 13(5): 807-812.

44. Dastani Z, Hivert MF, Timpson N, Perry JR, Yuan X, et al. (2012) Novel loci for adiponectin levels and their influence on type 2 diabetes and metabolic traits: a multi-ethnic meta-analysis of 45,891 individuals.PLoS Genet. 2012;8(3): e1002607.

45. Qi Y, Takahashi N, Hileman SM, Patel HR, Berg AH, et al. (2004) Adiponectin acts in the brain to decrease body weight.Nat Med 10(5): 524-529.

46. Barnea M, Shamay A, Stark AH, Madar Z (2006) A high-fat diet has a tissuespecific effect on adiponectin and related enzyme expression.Obesity 14(12): 2145-2153.

47. Yamane T, Kobayashi-Hattori K, Oishi Y (2011) A high-fat diet reduces ceramide synthesis by decreasing adiponectin levels and decreases lipid content by modulating HMG-CoA reductase and CPT-1 mRNA expression in the skin.Mol Nutr Food Res55 Suppl 2: S186-192.

48. Kasim-Karakas SE, Tsodikov A, Singh U, Jialal I (2006) Responses of inflammatory markers to a low-fat, high-carbohydrate diet: effects of energy intake. Am J Clin Nutr 83(4): 774-779.

49. Qi L, Rimm E, Liu S, Rifai N, Hu FB (2005) Dietary glycemic index, glycemic load, cereal fiber, and plasma adiponectin concentration in diabetic men.Diabetes Care 28(5): 1022-1028.

50. Combs TP, Berg AH, Rajala MW, Klebanov S, Iyengar P, et al. (2003) Sexual differentiation, pregnancy, calorie restriction, and aging affect the adipocytespecific secretory protein adiponectin.Diabetes 52(2): 268-276.

51. Escrivá F, Gavete ML, Fermín Y, Pérez C, Gallardo N,et al. (2007) Effect of age and moderate food restriction on insulin sensitivity in Wistar rats: role of adiposity.J Endocrinol 194(1): 131-141.

52. Kriketos AD, Gan SK, Poynten AM, Furler SM, Chisholm DJ, et al. (2004) Exercise increases adiponectin levels and insulin sensitivity in humans. Diabetes Care 27(2): 629-630.

53. Zeng O, Fu L, Takekoshi K, Kawakami Y, Isobe K (2007) Effects of short-term exercise on adiponectin and adiponectin receptor levels in rats. J Atheroscler Thromb 14(5): 261-265.

54. Hsu CH, Tsai TH, Kao YH, Hwang KC, Tseng TY, et al. (2008) Effect of green tea extract on obese women: A randomized, double-blind, placebo-controlled clinical trial. Clin Nutr 27(3): 363-370.

55. Sharabi Y, Oron-Herman M, Kamari Y, Avni I, Peleg E, et al. (2007) Effect of PPAR-gamma agonist on adiponectin levels in the metabolic syndrome: lessons from the high fructose fed rat model. Am J Hypertens 20(2): 206-210.

56. Yamamoto Y, Hirose H, Miyashita K, Nishikai K, Saito I, et al. (2002) PPAR gamma 2 gene Pro12Ala polymorphism may influence serum level of an adipocyte-derived protein, adiponectin, in the Japanese population. Metabolism 51(11): 1407-1409.

57. Kursawe R, Narayan D, Calil A M.G, Shaw M, Pierpont B, et al. (2010) Downregulation of ADIPOQ and PPAR $\gamma 2$ Gene Expression in Subcutaneous Adipose Tissue of Obese Adolescents With Hepatic Steatosis.Obesity 18(10): 1911-1917.

58. Catalano1 PM, Nizielski SE, Shao J, Preston L, Qiao L, et al. (2002) Downregulated IRS-1 and PPAR $\gamma$ in obese women with gestational diabetes: relationship to FFA during pregnancy.AJP - Endo 282(3): E522-533.

59. Choi JH, Banks AS, Estall JL, Kajimura S, Bostrom P, et al. (2010) Anti-diabetic drugs inhibit obesity-linked phosphorylation of PPARgamma by Cdk5. Nature 466(7305): 451-456.

60. Ohshima T, Koga H, Shimotohno K (2004) Transcriptional activity of peroxisome proliferator-activated receptor gamma is modulated by SUMO-1 modification. J Biol Chem 279(28): 29551-29557.

61. Schupp M, Clemenz M, Gineste R, Witt H, Janke J, et al. (2005) Molecular characterization of new selective peroxisome proliferator-activated receptor gamma modulators with angiotensin receptor blocking activity. Diabetes 54(12): $3442-3452$. 
62. Rangwala SM, Rhoades B, Shapiro JS, Rich AS, Kim JK, et al. (2003) Genetic modulation of PPARgamma phosphorylation regulates insulin sensitivity. Dev Cell 5(4): 657-663.

63. Burgermeister E, Seger R (2007) MAPK Kinases as Nucleo-Cytoplasmic Shuttles for PPAR $\gamma$. Cell Cycle 6(13): 1539-1548.

64. Gual P, Le Marchand-Brustel Y. Tanti JF (2005) Positive and negative regulation of insulin signaling through IRS-1 phosphorylation. Biochimie 87: 99-109.
65. Burns KA, Vanden Heuvel JP (2007) Modulation of PPAR activity via phosphorylation. Biochim Biophys Acta 1771(8): 952-960.

66. Hosooka T, Noguchi T, Kotani K, Nakamura T, Sakaue H, et al. (2008) Dok1 mediates high-fat diet-induced adipocyte hypertrophy and obesity through modulation of PPAR-gamma phosphorylation. Nat Med 14(2): 188-193. 